\title{
O PROCESSO DE EUTROFIZAÇÃO ARTIFICIAL NO LAGO PARANOÁ, BRASÍLIA, DF
}

\author{
Gustavo Macedo de Mello Baptista (*) \& Mário Diniz de Araújo Neto (**)
}

\begin{abstract}
This paper represent an academic exercise dealing with some index parameters of water quality using analytical field methods. In first instance it aims to demonstrate the praticalness of the methods as well as its level of precision. It was possible to estimate the influence of parameters like $\mathrm{NO}_{3}, \mathrm{pH}, \mathrm{OD}$ (dissolved oxygen), etc. for the determination of water quality of the Paranoá Lake wich serves as recipient of sewage from Brasilia and satellite towns of the Federal District/Brazil, with an estimated influx rate of 140 liters per second. Treatment of this quantity of sewage (during the time of our study) is very simple: just passing by a fence system. Conditions of eutrophication of this water body have become worse due to the inflow of clandestine sewage from houses along the the lake-side, wich contributes much to the increase of nutrients, especially phosphorus and nitrogen.

The obtained results were promising and served to stimulate further studies in the course "Practice of Field Studies", even not serving for a definite characterization of the waters. It is important to emphasize that neither results nor the analysis of the data are focused in this paper.

The high rate of eutrophication at the sampling stations can be observed using $\mathrm{NO}_{3}$ e $\mathrm{PO}_{4}$ as parameters. In that sense the following measures are recommended in order to maintain chemical and physical characteristics of the habitat:

1 - dredging of organic mud from the bottom of the lake, since it contains $80 \%$ of the phosphates of the slop, besides other nutrients;

2 - expansion or construction of new sewage treatment plants in order to prevent the inflow of sewage in natura in the lake and to satisfy the demand of the population;

3 - control of clandestine sewage of the houses at Lake South and North by the official environmental protection agencies punishing house owners with application of heavy fines;

4 - development of environmental education programs for scholars of all levels in order to arouse the conscience for preserving of water resources.
\end{abstract}

\section{INTRODUÇÃO}

A criação do lago Paranoá teve como objetivos principais amenizar o baixo teor de umidade do ar, nos meses de Abril a Setembro, e ser uma área de lazer para a população do Distrito Federal. Porém, nenhum dos objetivos foi alcançado, pois as correntes de ventos na região sopram à tangente do Plano Piloto levando consigo a umidade e a área de lazer não foi consolidada pois não houve a retirada total da cobertura vegetal original, ocasionando a decomposição de matéria orgânica, impedindo a prática do lazer.

O lago passou a ser um grande depositário de esgoto e o órgão responsável, CAESB (Companhia de Água e Esgoto de Brasília), lança atualmente cerca de 140 litros por segundo de esgoto in natura por segundo (Engevix 1988), passando apenas pelo processo de gradeamento. Além disso, os esgotos clandestinos de casas no Lago Sul e Norte vêm contribuindo bastante para o aumento de nutrientes, principalmente nitrogênio e fósforo.

Podemos afirmar que o processo de eutrofização artificial encontra-se hoje em estágio bastante avançado, prevendo-se a morte biológica do corpo hídrico em poucos anos. O processo é cíclico e exponencial.

\section{Ecossistemas de água doce}

Um ecossistema pode ser compreendido como a combinação entre fatores bióticos (seres vivos em geral) e abióticos (água, solo, e todos os componentes do ambiente que não possuem vida). Pode-se entender os diversos ecossistemas a partir de uma classificação bem genérica: ecossistemas terrestre e aquáticos. Como o estudo proposto analisa a eutrofização de um lago, é necessário entender melhor os ecossistemas de água doce.

Odum (1983) classifica os habitats de água doce em três séries:

a) Ecossistemas lênticos: de águas paradas;

b) Ecossistemas lóticos: de águas correntes;

c) Alagados: onde os níveis de água flutuam para cima e para baixo.

A maioria dos lagos, ou habitats lênticos, são de origem recente, datando desde de épocas glaciais. Porém, o homem pode interferir nos ambientes, represando cursos d'água para suprir alguma carência de massas hídricas, criando lagos artificiais.

A água desses reservatórios é utilizada, normalmente, para consumo da população, mas esse bem natural torna-se cada vez mais escasso, não pela sua ausência, mas pela perda da potabilidade. É comum em países subdesenvolvidos encontrar cursos d'água 
como depositários de lixo. O lago Paranoá não perfaz exceção.

\section{Poluição hídrica}

Como citado, os reservatórios sofrem um despejo constante de substâncias externas aos ecossistemas, ocasionando o que chamamos de poluição. Primeiramente, a poluição é percebida pelas alterações d'água. Sant'Anna \& Silveira (1990) encaram a poluição hídrica sob dois aspectos: o sanitário e o ecológico. No enfoque sanitário, a poluição é encarada como qualquer alteração química, física ou biológica d'água que afete direta ou indiretamente o homem. Na abordagem ecológica, poluição é entendida como qualquer alteração que cause ruptura nos habitats.

No estudo específico do lago Paranoá as alterações surgem pelo despejo de grandes quantidades de esgoto sem tratamento adequado. Apesar de existirem duas estações de tratamento, o crescimento populacional é maior do que se esperava. Na época da construção de Brasília, previa-se para o ano 2000 uma população para o Distrito Federal de aproximadamente 500.000 habitantes, porém os dados preliminares do censo de 1991 apontaram uma população de aproximadamente 1.600.000 habitantes, ou seja, a população já extrapola a casa de 1.100 .000 habitantes acima do previsto, quase dez anos antes. A capacidade de tratamento das duas ETE's é para 306.911 habitantes, nitidamente inferior à demanda, resultando numa descarga de 140 litros / segundo de esgoto não tratado. Essa quantidade de nutrientes lançadas diretamente no lago, associada à matéria orgânica submersa em processo constante de decomposição, acarreta uma eutrofização acelerada.

\section{$O$ processo de eutrofização artificial}

Esteves (1988) explica o processo de eutrofização $(e u=$ bem; trophos $=$ nutrientes $)$ como sendo o aumento da concentração de nutrientes responsável pelo aumento das populações.

Quanto à concentração de nutrientes, principalmente nitrogênio e fósforo, os ecossistemas lênticos podem ser classificados em: oligotróficos (baixa concentração), mesotróficos (média concentração), eutróficos (alta concentração) e hipereutróficos (altíssima concentração).

Quanto a sua origem, o processo pode ser classificado como natural ou artificial, ou seja, sem ou com atuação antrópica. Quando o processo acontece sem atuação humana, ele é lento, pois os principais agentes são as chuvas e as águas de escoamento superficial.

Quando a eutrofização surge a partir da ação humana, é chamada de artificial, antrópica ou cultural.

No lago Paranoá o processo de eutrofização é artificial e em estágio bastante avançado. Nesse caso o próprio ecossistema é artificial, pois o lago surgiu há 30 anos, aproximadamente, para suprir a carência de umidade do ar no período de Abril a Setembro (inverno frio e seco do clima tropical) e para servir de área de lazer à população formada principalmente por migrantes de regiões litorâneas. Além disso, as estações de tratamento dos esgotos não suprem as necessidades da população e lançam cerca de $71 \%$ do fosfato no lago (82 toneladas por ano), seguidas dos tributários (21\% ou $24 \mathrm{t} / \mathrm{ano})$, do escoamento superficial urbano e rural $(6,7 \%$ ou $8 \mathrm{t} / \mathrm{ano})$, das águas subterrâneas $(1 \%$ ou 1,5 t/ano) e da precipitação direta ( $0,7 \%$ ou 0,8 t/ano). Dos $100 \%$ lançados diretamente no lago, $80 \%$ ficam retidos no ecossistema e apenas $20 \%$ são exportados do ambiente pela barragem.

Cordeiro Neto \& Dutra Filho (1981) apontam que desde 1959, quando da formação do lago artificial do Paranoá, o mesmo já apresentava nítidos sinais de um processo crescente de eutrofização artificial, apesar de ainda encontrar-se em estágio oligotrófico, com grande diversidade de algas clorofíceas. Porém esse processo se intensifica com a floração de algas cianofíceas como a Anabaenopsis raciborskii que reduzem as possibilidades de utilização do corpo hídrico. Essa floração é explicada pela má utilização da bacia de drenagem do Paranoá e pelo maciço lançamento de efluentes.

\section{MATERIAIS E MÉTODOS}

Para a determinação de áreas eutrofizadas dentro de um corpo hídrico é necessário adotar alguns parâmetros de análise físico - química. Após a coleta dos dados pode-se mapear a eutrofização utilizando bases cartográficas, ou então sensoriamento remoto.

\section{Parâmetros físico-químicos}

Alguns aspectos têm de ser ressaltados na análise de eutrofização. Foram escolhidos alguns parâmetros para a percepção do grau de poluição hídrica no corpo do lago Paranoá. São eles:

* turbidez;

* temperatura d'água;

* nitratos;

$* \mathrm{pH}$

* oxigênio dissolvido.

\section{Turbidez}

Branco \& Rocha (1977) definem turbidez d'água como sendo o grau de redução que a luz sofre ao atravessá-la, por efeito da presença da matéria em suspensão, seja orgânica ou inorgânica. Para a aferição da turbidez utilizou-se o disco de Secchi, uma superfície sintética branca circular com um peso embaixo, presa a uma corda. Mergulha-se o disco até o momento onde não ocorre mais a visualização do mesmo. Retira-se, então, o disco d'água e mede-se o comprimento da corda que foi imergida.

\section{Temperatura da água}

Quando a temperatura superficial do corpo hídrico sofre constantes variações, esta torna-se imprópria para abastecimento, caracterizando-se, então, a poluição. Para tal medida utilizou-se um termômetro colocado à 
flor d'água por alguns minutos. Após uns três minutos, aproximadamente, realiza-se a leitura.

\section{Nitratos}

O processo de eutrofização artificial caracteriza-se pelo aumento significativo de nutrientes, principalmente nitratos e fosfatos, em uma massa hídrica. De acordo com o Water Quality Criteria (McKee \& Wolf 1968), o limite recomendado de nitratos é de $10 \mathrm{mg} / \mathrm{l}$. Em lagos e represas entretanto, os índices acima de $0,3 \mathrm{mg} / \mathrm{l}$ de nitrogênio podem apresentar problemas, pois propiciam a proliferação excessiva de algas (Branco 1971). Para medir os gradientes de nitratos utilizou-se um kit de análise: coloca-se a amostra em dois tubos de ensaio, adicionando reagente em um deles. Tampa-se o tubo e agita-se para acelerar a reação. Colocam-se os dois tubos tampados na caixa de medição e através da variação de tonalidades verifica-se as concentrações de $\mathrm{NO}_{3}$.

$p H$

Os ecossistemas lênticos não eutrofizados, ou seja, oligotróficos, apresentam valores de $\mathrm{pH}$ entre 6,0 e 8,5 . Nos lagos eutrofizados os valores de $\mathrm{pH}$ normalmente apresentam-se fora desta faixa. $\mathrm{O}$ processo de medida é bem parecido com o de $\mathrm{NO}_{3}$. Coleta-se a amostra em dois tubos de ensaio. $\mathrm{O}$ primeiro é tampado e no segundo adiciona-se cinco ou seis gotas do reagente que acompanha okit. Após agitar colocamse os tubos na caixa de medição para determinar o $\mathrm{pH}$.

\section{Oxigênio dissolvido (OD)}

O oxigênio dissolvido não possui valores definidos para o tratamento d'água e nem para o abastecimento populacional, pois não é parâmetro relevante para tais fins, porém é um dos aspectos mais importantes para o estudo de eutrofização e poluição. Coloca-se água num frasco e adiciona-se o reagente $n^{\circ} 1$ do kit. Agita-se e adiciona-se o reagente $\mathrm{n}^{\circ} 2$ e espera-se algum tempo. Após dois a três minutos adiciona-se o reagente $n^{\mathbf{o}} 3$ do kit, transferindo a água para um tubo de ensaio. Coloca-se, então, o reagente $n^{\circ} 4$ no restante da amostra do frasco e agita-se até a água ficar transparente. É importante salientar que a quantidade de gotas do reagente deve ser adicionada cautelosamente, pois o número de gotas equivale à concentração de oxigênio dissolvido na água.

\section{Precisão dos kits de análise}

Para a aferição dos dados de $\mathrm{NO}_{3}, \mathrm{pH}$ e oxigênio dissolvido, foram utilizados kits da $\mathrm{HACH}$, empresa americana que comercializa materiais de análise.

Cada kit trás consigo um manual de utilização, porém o erro de cada um não vem expresso. No catálogo dos produtos encontramos o desvio padrão dos kits, ou seja, o erro médio das leituras. Para a parte de análise d'água o erro médio é de $6 \%$, enquanto que os instrumentos mais precisos usados para análise apresentam um erro de $3 \%$, aproximadamente.

\section{Tratamento de imagens de satélite}

A utilização de imagens de satélite para a percepção da eutrofização artificial em habitats lênticos é um dos recursos para o mapeamento do processo. Os sensores em satélites captam a reflectância de ondas eletromagnéticas, que variam de acordo com o comprimento, desde a luz visível até o infravermelho.

Segundo Rosa (1990), a reflectância d'água limpa diminui com o aumento dos comprimentos de onda, ou seja, nas faixas mais utilizadas em sensoriamento remoto, verificam-se as maiores reflectâncias na região do visível, mais especificamente nos comprimentos mais próximos do azul e verde, decrescendo em direção ao infravermelho.

Quando há presença de sedimentos orgânicos ou inorgânicos, o pico de reflectância desloca-se para os maiores comprimentos de ondas, mais próximas do infravermelho termal. A reflectância d'água eutrofizada é maior que d'água limpa.

Para a utilização do recurso sensoriamento remoto é necessário que se faça a aferição de parâmetros físico - químicos para detectar as áreas mais eutrofizadas, para realizar a classificação de todas as áreas com o mesmo albedo. É importante salientar ainda que as imagens devem ser de dias em estações secas ou com baixos gradientes de precipitação pluviométrica para evitar a revolução das águas, o que pode alterar as informações.

A leitura das imagens pode sofrer algumas alterações, pois além da radiação que chega à superfície ser direta e difusa, a absorção por elementos atmosféricos (vapor d'água, ozônio, dióxido de carbono, etc.) pode influenciar a leitura das informações. Dentro das bandas do ultravioleta e luz visível, o principal responsável pela absorção é o ozônio, enquanto que na banda do infravermelho, o vapor d'água e o dióxido de carbono são os principais responsáveis (Rosa 1990).

As imagens utilizadas nesse trabalho são do satélite francês SPOT (Système Probatoire d'Observation). Segundo Loch (1989), o SPOT apresenta-se de dois modos: o multiespectral e o pancromático. O utilizado foi o modo multiespectral em bandas com comprimento de onda variando de 0,50 a $0,89 \mu$, tendo uma resolução espacial de $20 \mathrm{~m}$, passando pelo mesmo ponto num ciclo de 26 dias.

\section{RESULTADOS}

Para analisarmos a eutrofização do lago Paranoá adotamos alguns pontos para a coleta dos dados, realizadas nos dias 11/06, 11/09, 02/10, 08/10, 19/10 e 23/10/92. Os pontos foram: Ribeirão do Torto, Saco do Bananal (ponte do Bragueto), Barragem do Paranoá, ETE1 e Ribeirão do Gama (Figura 1).

\section{Parâmetros físico-químicos}

\section{Turbidez}

No ponto 1 - Ribeirão do Torto, tributário do lago 
situado entre o Lago Norte e o Setor de Mansões do Lago Norte - a penetração de luz variou de 23 a $62 \mathrm{~cm}$ no período de coleta de dados. É importante lembrar que o menor valor foi coletado no dia 23/10, quando o período de chuvas já havia se iniciado.

No ponto 2 - Saco do Bananal, ponte do Bragueto a variação de turbidez foi de 59 a $90 \mathrm{~cm}$. Apesar do acelerado processo de assoreamento embaixo da ponte, as coletas foram realizadas de barco, possibilitando a análise sem interferência significativa dos sedimentos do fundo.

No ponto 3 - Barragem do Paranoá, o local mais fundo do lago com cerca de 45 metros de profundidade - a variação de turbidez oscilou em torno de 50 a 60 $\mathrm{cm}$.

$\mathrm{Na}$ área mais eutrofizada do lago, a ETE 1 - situada próxima à ponte das Garças, nosso $4^{\circ}$ ponto - a turbidez variou entre 9 a $50 \mathrm{~cm}$.

O local onde a diversidade de fauna nos chama a atenção, pois encontramos capivaras (Hydrochoerus hydrochaeris), jacarés (Caiman yacare), martim pescadores - verdes (Chloroceryle amazona), biguás (Phalacrocorax olivaceus) (Antas \& Cavalcanti 1988) entre outros, é o ponto 5 ou Ribeirão do Gama, localizado próximo à QI. 17 do Lago Sul. Nele, a oscilação de turbidez encontrou-se entre 50 e $75 \mathrm{~cm}$.

Podemos perceber que a variação de turbidez no lago Paranoá, através dos pontos de coleta, oscila entre 9 a $90 \mathrm{~cm}$. É nítido que a diminuição da zona eufótica é ocasionada pela grande quantidade de sedimentos incorporados à massa hídrica. Porém a redução que a luz sofre ao atravessar a água é considerada como parâmetro de qualidade meramente estético (Branco \& Rocha 1977). A turbidez pode ser tratada em estações através de processos de coagulação, sedimentação e filtração.

\section{Temperatura da água}

A variação de temperatura superficial d'água é muito pequena nos diversos pontos do lago.

No ponto 1 a amplitude térmica é muito pequena: a máxima está em torno de $25^{\circ} \mathrm{C}$ e a mínima em $23^{\circ} \mathrm{C}$.

No ponto 2 a máxima encontrou-se em $26^{\circ} \mathrm{C}$, aproximadamente, e a mínima em $22^{\circ} \mathrm{C}$.

Já no ponto 3 a amplitude é maior, porém não expressa grande variação de temperatura. A máxima atinge a casa dos $27^{\circ} \mathrm{C}$ e a mínima, a casa dos $18^{\circ} \mathrm{C}$.

O ponto 4 apresentou variação entre $20^{\circ} \mathrm{C}$ e $25^{\circ} \mathrm{C}$.

$\mathrm{O}$ último ponto apresentou uma das maiores amplitudes térmicas: a máxima atingiu valores aproximados acima de $30^{\circ} \mathrm{C}$ e a mínima em torno dos $22^{\circ} \mathrm{C}$.

Como citado anteriormente, quando ocorrem variações da temperatura superficial d'água, ela tornase imprópria para o abastecimento populacional. Podemos perceber, também, que a variedade de fauna encontrada no ponto $4 \mathrm{e}$, principalmente, no ponto 5 está intrinsecamente relacionada a uma maior quantidade de nutrientes. Dizer que o aparecimento de garças, por exemplo, indica que a despoluição se faz

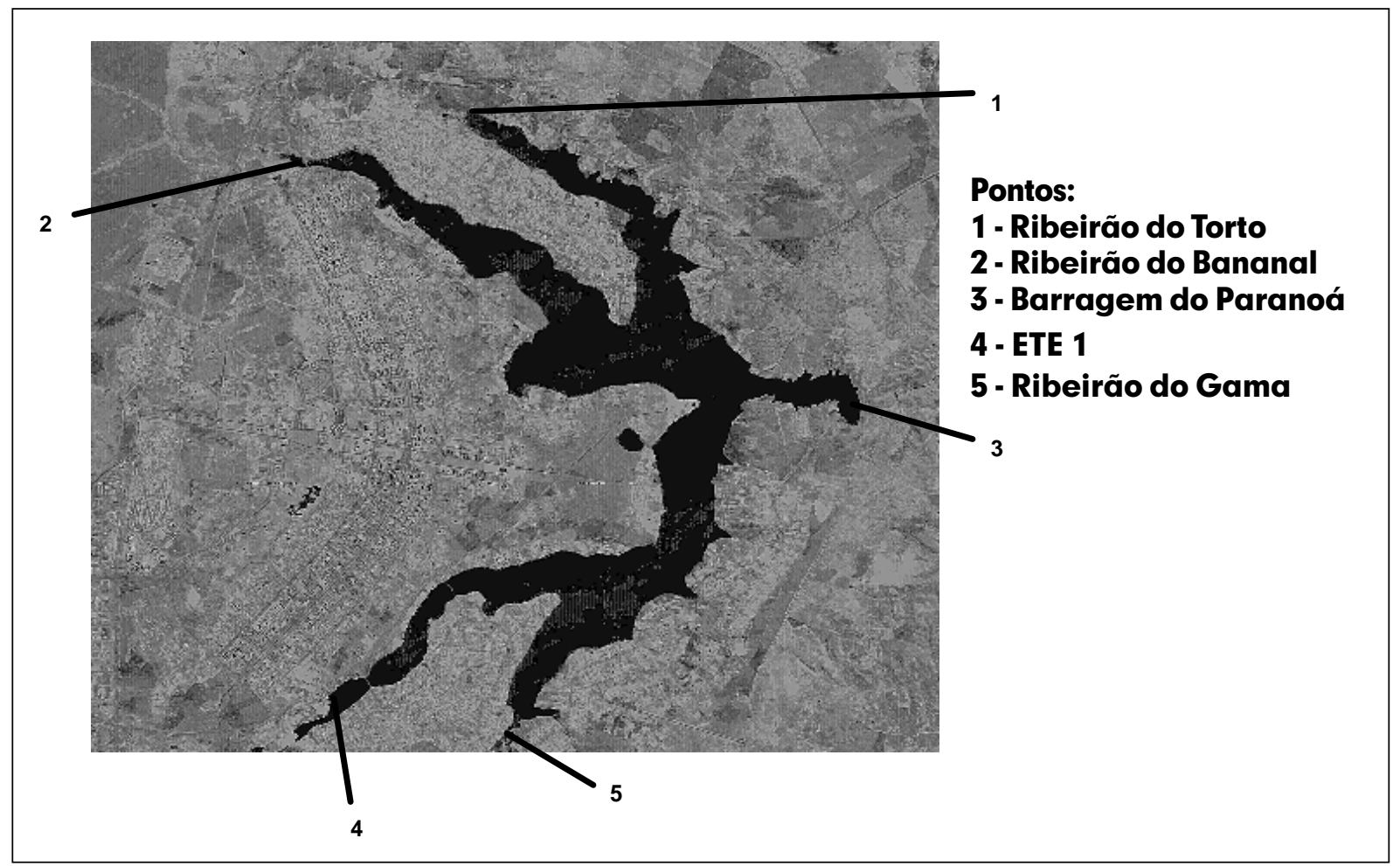

Figura 1 - Lago Paranoá - Distrito Federal, 1992. Pontos de Coleta (organizado por Gustavo Macedo de M. Baptista a partir da banda 3 do SPOT - Brasília 18/08/88).

Figure 1: Paranoá Lake, Federal District, Brazil (1992) with sampling stations (compiled by Gustavo Macedo de M. Baptista, using SPOT image, band 3; taken Aug. 18, 1988). 
presente é errado, pois quanto maior o despejo de efluentes, maior será o tamanho da comunidade biótica, seja de alevinos ou de garças.

As maiores amplitudes podem informar os pontos mais eutrofizados.

\section{Nitratos}

Pudemos verificar que o Water Quality Criteria (1968) considera o limite de nitrato recomendado em torno de $10 \mathrm{mg} / \mathrm{l}$ e Branco (1971) recomenda um limite bem inferior para ecossistemas lênticos, em torno de $0,3 \mathrm{mg} / \mathrm{l}$, pois qualquer concentração superior pode acelerar o processo de proliferação de algas.

No ponto 1 podemos observar uma concentração variando de 25 até $32 \mathrm{mg} / \mathrm{l}$.

No ponto 2 a variação é bem maior: o limite mínimo foi de aproximadamente $18 \mathrm{mg} / \mathrm{l}$ e o máximo de 43 $\mathrm{mg} / \mathrm{l} \mathrm{em}$ três dias de coleta de amostras.

O ponto 3 apresentou uma variação oscilando entre 23 e $31 \mathrm{mg} / \mathrm{l}$.

Já o ponto 4 apresentou uma variação nos níveis de nitrato acima de $13 \mathrm{mg} / \mathrm{l}$ atingindo sua maior concentração em torno de $31 \mathrm{mg} / \mathrm{l}$.

No ponto 5 a variação encontra-se entre 23 e 29 $\mathrm{mg} / \mathrm{l}$.

O resultado das amostras coletadas em dias diferentes nos informa que a concentração média de $\mathrm{NO}_{3}$ no lago Paranoá é superior à recomendada pelo WQC. O nível de eutrofização é bastante sentido nesse parâmetro, pois, como já vimos, o processo é caracterizado pelo aumento de nutrientes como nitrogênio e fósforo.

\section{$p H$}

O nível recomendado de $\mathrm{pH}$ para abastecimento está situado entre os valores 6,0 e 8,5, porém quanto menos ácido o pH, melhor a qualidade do corpo hídrico.

No ponto 1 a variação dos índices de $\mathrm{pH}$ esteve acima de 7,0 e a máxima, encontrada no dia 11/09, atingiu o nível 9,0.

No ponto 2 a máxima foi de 7,7 e a mínima de 6,5 , ou seja, dentro dos limites recomendados.

No ponto 3 a variação esteve entre 7,0 e 9,0.

No ponto 4 os níveis foram os menores, ou seja, mais ácidos: os índices menores atingiram a casa dos 4,0 e os máximos estiveram próximos a 7,0.

O ponto 5 manteve-se constante nos últimos dias de coleta, em torno de 6,4. A máxima registrada foi de 7,6 e a mínima de 6,0 .

Em termos de $\mathrm{pH}$ apenas a ETE 1 apresentou dados inferiores aos recomendados, porém deve-se ressaltar que há um predomínio de valores ácidos abaixo de 7,0.

\section{Oxigênio dissolvido $(O D)$}

Como o processo de eutrofização caracteriza-se pelo aumento de nutrientes, há uma tendência de aumento no número de indivíduos das populações ecossistêmicas. Esse aumento representa uma disputa pelos nutrientes e pelo oxigênio dissolvido na água. Quanto maior o número de indivíduos respirando, menor a concentração de OD, ocasionando um aumento considerável no índice de mortalidade. Os organismos que morrem, sofrem a ação dos decompositores, que vão liberar, novamente, os nutrientes consumidos e os incorporados à biomassa. Daí podemos afirmar que o processo é cíclico e exponencial.

O Water Quality Criteria recomenda uma concentração superior a $4 \mathrm{mg} / \mathrm{l}$, porém nas áreas mais eutrofizadas do lago os índices são inferiores aos considerados razoáveis.

Nesse trabalho não foram incluídos dados de outros anos, porém em agosto de 1991, o autor, auxiliado por um grupo de alunos do Colégio Objetivo, no Projeto Paranoá, encontrou no ponto 4 um índice de OD igual a zero. Quando aciona-se o motore do barco, a hélice realiza uma troca gasosa entre o ar atmosférico e a água. Percebendo a entrada de oxigênio na água, os peixes deslocam-se com tanta velocidade que acabam entrando no barco. O desespero pelo oxigênio é bem nítido nas áreas mais eutrofizadas.

No ponto 1 os índices estiveram acima do recomendado pelo WQC. Os maiores estiveram em torno de $10 \mathrm{mg} / \mathrm{l}$ e os menores acima de 7,0 mg/l.

No ponto 2 os índices apresentaram-se constantes nos quatro últimos dias de coleta, em torno de 9,0 $\mathrm{mg} / \mathrm{l}$. A máxima atingiu a casa dos $10 \mathrm{mg} / \mathrm{l}$ e a mínima situou-se próximo a $8,0 \mathrm{mg} / 1$.

$\mathrm{O}$ ponto 3 apresentou os maiores índices de concentração de oxigênio dissolvido, atingindo 13 $\mathrm{mg} / \mathrm{l}$, a mínima encontrada foi de 7,0 mg/l.

Já o ponto 4 apresentou os menores índices. A máxima foi obtida no dia 02/10 com um índice de 6,0 $\mathrm{mg} / \mathrm{l}$ e a mínima obtida no dia 08/10 com um índice de 2,0 mg/l.

$\mathrm{O}$ ponto 5 apresentou índices superiores ao recomendado pelo WQC: a variação situa-se entre 6,0 e $10,0 \mathrm{mg} / \mathrm{l}$.

\section{Tratamento de imagens de satélite}

A partir da coleta e do tratamento estatístico dos dados pudemos notar que nas áreas mais eutrofizadas, em geral, há uma maior proliferação de algas e uma maior quantidade de sedimentos incorporados à massa d'água, ocasionando uma maior turbidez.

Levando em conta que o comportamento espectral d'água varia de acordo com o grau de limpeza da mesma, pudemos realizar a análise de turbidez a partir de imagens orbitais.

Utilizou-se as três bandas do modo multiespectral do SPOT, onde a primeira abrange a faixa do espectro que vai de 0,50 a 0,59 (verde), a segunda de 0,61 a 0,68 (vermelho) e a terceira de 0,79 a 0,89 (infra vermelho). A imagem utilizada data do dia 18 de agosto de 1988, no turno da manhã, período seco sem nenhuma precipitação registrada. Foram utilizados como área de treinamento, ou seja, a área que vai ser analisada para que o sistema possa classificar todos os pontos de uma mesma classe com mesma reflectância em toda 
imagem, as estações de tratamento de esgoto e a barragem do Paranoá.

Após escolhidas as áreas de treinamento foi feita uma classificação supervisionada de imagem através do método da máxima verossimilhança, que assume que a distribuição dos pontos da área de treinamento por cada categoria tem distribuição normal. Com esse método calcula-se a probabilidade estatística de cada ponto ou pixel pertencer à classe. Os pixels que não estão dentro da classe não são classificados.

Como resultado obtivemos uma imagem que representa a concentração de sedimentos em diversos pontos do corpo hídrico e como a maioria dos mesmos estão ao sabor da corrente há um deslocamento em direção à barragem (Figura 2).

\section{DISCUSSÃO}

Branco (1991) define poluição como sendo a colocação de energia e matéria no lugar errado, e no caso do Paranoá, a poluição vem como consequiência do processo de fertilização das águas, ou eutrofização.

Essa eutrofização surge a partir do aporte de nitratos e fosfatos na água advindos do despejo de efluentes ou pela utilização de fertilizantes próximos à margem.

Nossos dados apresentam uma variação na concentração de $\mathrm{NO}_{3}$ acima de $10 \mathrm{mg} / \mathrm{l}$, atingindo em determinados pontos valores superiores a $45 \mathrm{mg}$ / 1, com concentração média de $27,3 \mathrm{mg} / \mathrm{l}$. Esteves (1988) apresenta como exemplos lagos com concentrações diferentes de $\mathrm{NO}_{3}$.

O lago Silser, na Suíça, é considerado oligotrófico e apresenta uma concentração média de $0,75 \mathrm{mg} / \mathrm{l}$ na lâmina superficial. O lago Keller, na Alemanha, possui um grau de eutrofização avançado e os níveis de nitrato oscilam na casa de 15,5 a $16 \mathrm{mg} / \mathrm{l}$.

Mellanby (1982) fala sobre os níveis de nitrato em dois rios britânicos: o rio Lee e o Tâmisa. A concentração de nitrato do rio Lee extrapola o nível de $10 \mathrm{mg} / \mathrm{l}$, enquanto que o Tâmisa não ultrapassa 9 $\mathrm{mg} / \mathrm{l}$ (dados coletados entre 1975 e 1980).

Pudemos perceber que os níveis de nitrato no lago Paranoá são bastante superiores aos dos exemplos citados acima. O lago Keller é considerado eutrófico e os níveis são inferiores aos do Paranoá.

A eutrofização surge também pelo despejo de fosfatos. Cordeiro Neto \& Dutra Filho (1988) falam de um aporte anual de 116 toneladas de fosfatos, com concentração média de $0,08 \mathrm{mg} / \mathrm{l}$, no lago Paranoá.

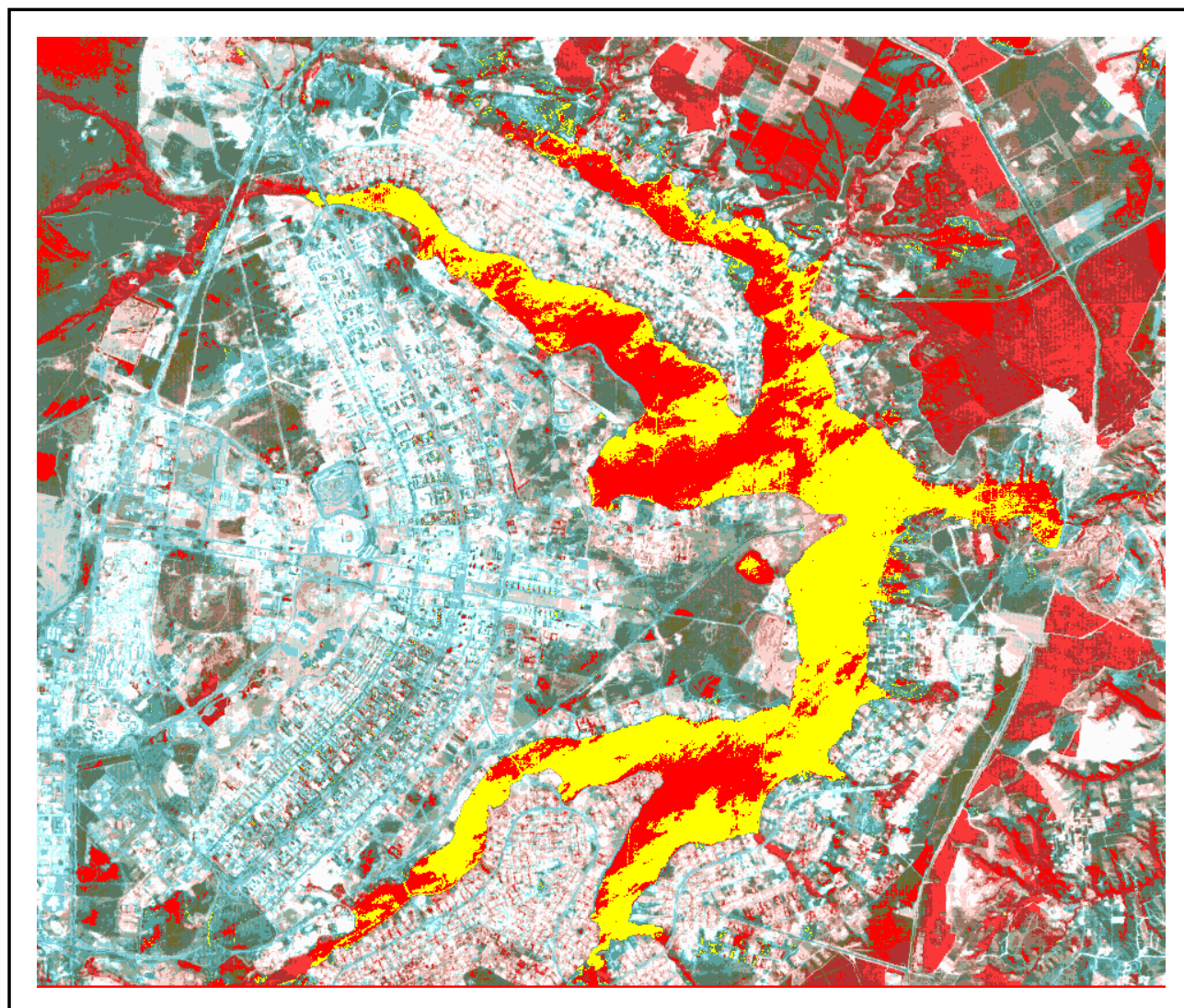

Figura 2: Lago Paranoá - Brasília, 1992. Diferença de turbidez por sensoriamento remoto. Resultado da Classificação Supervisionada usando o método da Máxima Verossimilhança sobre as três bandas do satélite SPOT. Imagem datada de 18 de agosto de 1988. Percebe-se concentração de sedimentos incorporados à massa hídrica (cinza claro) e as áreas de menor turbidez (cinza escuro) (organizado por Gustavo Macedo de M. Baptista).

Figure 2:Paranoá Lake, Brasília (1992). Differentiation of turbidity by remote sensing. Result of a Supervised Classification, using the Maximum Verisimilitude Method with three bands of the SPOT satellite. Image taken

Aug. 18, 1988. Note the sediments within the lake (light gray) and regions of less turbidity (dark) (Compiled by Gustavo Macedo de M. Batista). 
O lago Silser (Suíça) apresenta uma concentração média de 0,06 mg/l e o lago Plönde (Alemanha), 3,10 $\mathrm{mg} / \mathrm{l}$ (eutrófico). Porém, os dados de fosfatos não foram levantados nesse trabalho.

Como conseqüência da eutrofização surge o aumento das populações e a redução do oxigênio dissolvido. A morte de espécies é conseqüência imediata dos índices baixos de OD.

Pudemos observar que os índices de OD em alguns pontos são críticos, ou seja, $2 \mathrm{mg} / \mathrm{l}$.

Conti (1986) fala sobre o oxigênio como importante fonte de depuração; segundo ela, o nível de poluição hídrica pode ser medido em DBO (demanda biológica de oxigênio), ou seja, "o número de miligramas de oxigênio por litro d'água necessários para transformar moléculas complexas em moléculas simples de gás carbônico, água, sais minerais, etc."

Como é possível recuperar o habitat se, além de lêntico (água parada, fluxo pequeno), a concentração de oxigênio dissolvido é muito baixa? A utilização de um depurador artificial é a solução proposta por Conti (1986).

$\mathrm{O}$ pH do lago Paranoá apresenta um valor médio de 7,15 pelos dados desse trabalho, porém encontramos valores inferiores a 7 indicando uma acidez no ponto de coleta. Esse $\mathrm{pH}$ ácido nos mostra que o processo de decomposição está acontecendo dentro do habitat.

Analisando cada ponto em separado, teremos a comprovação do elevado grau de eutrofização no lago Paranoá.

O nosso primeiro ponto, o ribeirão do Torto, apresentou os seguintes valores médios:

a)Turbidez: $48,5 \mathrm{~cm}$.

b) Temperatura superficial: $22,83^{\circ} \mathrm{C}$.

c) Concentração de $\mathrm{NO}_{3}: 27,84 \mathrm{mg} / 1$.

d) $\mathrm{pH}: 7,78$

e) Oxigênio dissolvido: $8,66 \mathrm{mg} / \mathrm{l}$.

Com uma vazão média de $2,807 \mathrm{~m}^{3} / \mathrm{s}$ (dados de 1959 à 1974 - CODEPLAN 1976), o ribeirão do Torto apresentou-se com turbidez média que pode nos indicar uma ação do fluxo d'água carregando os sedimentos incorporados à massa hídrica. A concentração média de nitrato coletada no ponto é de $27,84 \mathrm{mg} / \mathrm{l}$, o que indica um elevado grau de eutrofização. É importante salientar que a concentração é medida na água, mas grande parte encontra-se incorporada à biomassa. $\mathrm{O}$ $\mathrm{pH}$ do ponto encontra-se num valor de 7,78, dentro do estipulado pelo Water Quality Criteria, porém o acúmulo de lixo nas margens do ribeirão é preocupante, além do rápido processo de assoreamento, que, em menos de três anos, apresenta a formação de ilhas. A temperatura superficial média é de $22,83^{\circ} \mathrm{C}$, e a variação é muito pequena. No parâmetro oxigênio dissolvido, a concentração média é superior a $8 \mathrm{mg} / \mathrm{l}$ o que pode ser entendido pelo número de indivíduos inferior ao dos pontos de menor concentração de OD.

$\mathrm{O}$ ponto 2, o ribeirão do Bananal, apresenta uma curiosidade com relação aos dados: baixa turbidez $(73,75 \mathrm{~cm}$ - média dos dados coletados) e elevada concentração de nitratos $(32,56 \mathrm{mg} / \mathrm{l})$. Essa curiosidade surge, pois havendo uma concentração média de nitratos deveríamos encontrar no ponto uma maior turbidez, causada pela proliferação de organismos planctônicos, principalmente por fitoplâncton. Isso pode ser explicado a partir da vazão média do ribeirão, algo em torno de $2,305 \mathrm{~m}^{3} / \mathrm{s}$, que pode levar consigo essas partículas que reduzem a penetração da luz no corpo hídrico. Um outro valor que pode explicar tal fato é a concentração média de OD, cerca de $9 \mathrm{mg} / \mathrm{l}$, que nos indica um menor consumo devido a um número também menor de indivíduos. $\mathrm{O}$ pH do ponto é ácido, cerca de 6,75 (valor médio), porém, apesar de indicar um possível processo de decomposição em andamento, encontra-se dentro dos limites recomendados, enquanto que a variação de temperatura é pequena e a média situa-se na casa dos $23^{\circ} \mathrm{C}$.

O ponto 3, a barragem do Paranoá, apresenta-se, nos dados coletados, com uma turbidez média de 45,16 $\mathrm{cm}$, podendo ser entendida a partir de outros parâmetros físico - químicos. Apresenta a maior concentração média de oxigênio dissolvido, algo em torno de 10, 83 $\mathrm{mg} / \mathrm{l}$. Esse alto índice pode ser explicado pela migração dos fluxos d'água, pois é o local de vazão do lago. Além disso, as comunidades nesse local devem ser em menor número de indivíduos e o processo de decomposição em estágio mais reduzido, pois o valor médio de $\mathrm{pH}$ é 8,33 , um valor básico, dentro do limite recomendado. A temperatura média é de $22,16^{\circ} \mathrm{C}$, porém a amplitude térmica é uma das mais altas em todos os pontos de coleta, algo em torno de $9^{\circ} \mathrm{C}$. A concentração média de nitrato é bastante elevada como em todo o habitat atingindo a casa dos $27,27 \mathrm{mg} / \mathrm{l}$.

O ponto 4, ETE 1, apresenta-se como o local mais crítico, pois ali encontramos a menor concentração média de oxigênio dissolvido: $4 \mathrm{mg} / \mathrm{l}$. Isso pode ser entendido, pois, neste local a estação lança cerca de 60 1/s de esgoto sem tratamento, além disso a liberação de $\mathrm{H}_{2} \mathrm{~S}$ e $\mathrm{CH}_{4}$ (gás sulfídrico e gás metano) é percebida visualmente pela formação de bolhas na água. Isso implica, também, na acidez d'água, algo em torno de um valor médio de 6,31. A turbidez no local também é a mais alta encontrada nas análises realizadas, cerca de $36,33 \mathrm{~cm}$, devido à quantidade de partículas em suspensão e pelo desprendimento da lama orgânica do fundo. Esse fenômeno pode ser entendido, pois essa lama está saturada em metano e gás sulfídrico. A concentração média de nitrato foi a mais baixa, 24,2 $\mathrm{mg} / \mathrm{l}$, pois grande parte do nitrato está incorporada à biomassa. A temperatura média foi de $22,25^{\circ} \mathrm{C}$.

O último ponto de coleta de dados, o ribeirão do Gama foi um dos locais onde o processo de assoreamento foi mais sentido, principalmente pelo deslocamento do barco. A turbidez apresentou-se com o segundo maior valor médio, $59,16 \mathrm{~cm}$. Analisandose a vazão médio do ribeirão, $1,729 \mathrm{~m}^{3} / \mathrm{s}$, percebemos que os organismos que estão ao sabor da corrente são deslocados em direção ao meio do lago, aumentando, assim, a penetração da luz na água. Foi o ponto de 
maior temperatura média dos dados coletados $\left(25,83^{\circ} \mathrm{C}\right)$, onde a variação de temperatura nos seis dias de coleta, associada à diversidade de espécies, nos indicam uma média concentração de nutrientes na água, comprovada pela concentração média de nitrato $(24,86$ mg/l). Considerou-se como média concentração de nutrientes, pois foi o segundo menor valor de $\mathrm{NO}_{3}$ registrado e pela concentração de $\mathrm{OD}$, algo em torno de $8 \mathrm{mg} / \mathrm{l}$. O pH apresentou o valor 6,58, ácido, porém, dentro dos limites do Water Quality Criteria.

\section{CONCLUSÕES}

Pudemos notar que a situação do corpo hídrico do lago Paranoá é bastante crítica. O lago, em menos de 40 anos, encontra-se em um estágio hipereutrófico.

Além dos efluentes lançados sem tratamento, a cobertura vegetal de cerradão e mata ciliar que existia antes do alagamento não foi totalmente retirada e a matéria orgânica encontra-se em processo de oxidação e decomposição, liberando também nutrientes.

Um dos problemas mais críticos no Distrito Federal hoje é a captação de recursos hídricos para o abastecimento da população. Além dos mananciais serem escassos em número, a redução da potabilidade dos habitats aquáticos é uma realidade.

No projeto dessa pesquisa foi lançada a hipótese de que o homem é o grande responsável pela elevada degradação desse ecossistema. Pode ser comprovado que sem a ação antrópica o nível de eutrofização seria praticamente nulo.

Sugerimos para a manutenção do habitat, algumas medidas que podem ser adotadas pelos órgãos competentes:

a) dragagem da lama orgânica retida no fundo do lago, pois nela estão $80 \%$ dos despejos de fosfatos, entre outros nutrientes;

b) construção ou ampliação de novas estações de tratamento para evitar os lançamentos de esgotos in natura no lago e para cumprir a demanda atual da população;

c) fiscalização, por parte dos órgãos de controle ambiental, de esgotos clandestinos de casa nos Lagos Sul e Norte, punindo os responsáveis com pesadas multas;

d) desenvolver programas de educação ambiental para estudantes de todos os níveis afim de despertar a consciência para a preservação dos recursos hídricos.

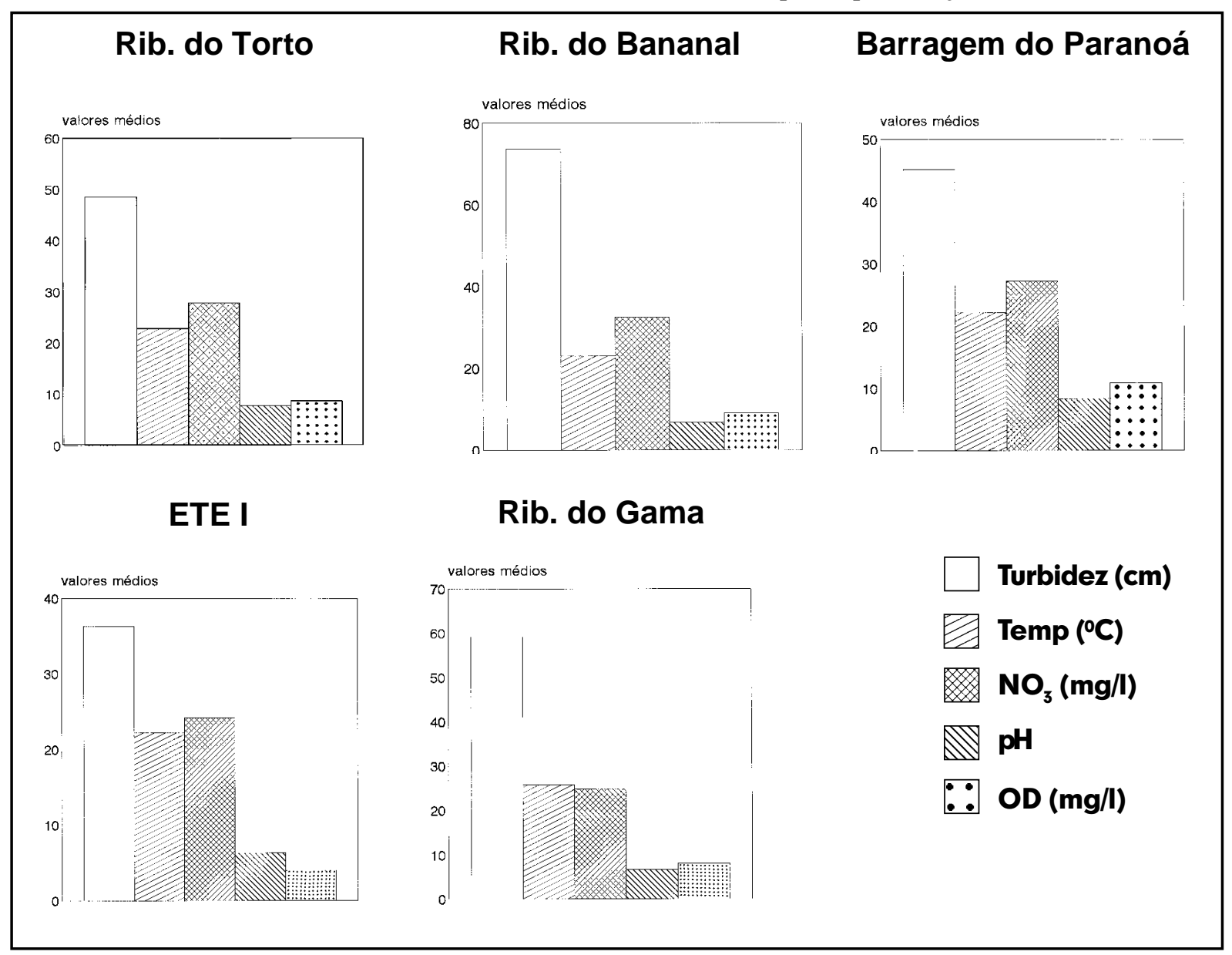

Figura 3: Parâmetros de eutrofização das águas do Lago Paranoá, Brasília, Distrito Federal, baseados em medições de Junho a Novembro de 1992.

Figure 3: Eutrophication parameters of the waters of Lake Paranoá, Federal District, Brazil, based on measuring during the period June through November 1992. 
É importante salientar que, caso não sejam adotados programas para a recuperação do lago, é bem provável que o mesmo não dure mais que vinte anos sendo sua morte irreversível.

\section{REFERÊNCIAS BIBLIOGRÁFICAS}

ANTAS, P.T.Z. \& CAVALCANTI, R.B. 1988. Aves comuns do Planalto Central. Brasília, Ed. UnB.

BRANCO, S. M. 1971. Hidrobiologia aplicada à engenharia sanitária. São Paulo, CETESB.

BRANCO, S. M. 1991. O meio ambiente em debate. São Paulo, Ed. Moderna.

BRANCO, S.M. \& ROCHA, A. A. 1977. Poluição, proteção e usos múltiplos de represas. São Paulo, Ed. Edgard Blücher Ltda.

CODEPLAN. 1976. Diagnóstico do espaço natural do Distrito Federal. Brasília, CODEPLAN.

CONTI, L. 1986. Ecologia: capital, trabalho e ambiente. São Paulo, Ed. HUCITEC.
CORDEIRO NETTO, O. M. \& DUTRA FILHO, D. 1988. O aporte de fósforo ao Lago Paranoá. In: ESTEVES, F. A. Fundamentos de Limnologia. Rio de Janeiro, Ed. Interciência / FINEP.

ENGEVIX. 1988 . Plano diretor de águas. Brasília, ENGEVIX.

ESTEVES, F.A. 1988. Fundamentos de limnologia. Rio de Janeiro, Ed. Interciência / FINEP.

LOCH, C. 1989. Interpretação de imagens aéreas: noções básicas e algumas aplicações nos campos profissionais. Florianópolis, EDUFSC.

McKEE, J.E. \& WOLF, H. W. 1977. Water quality criteria. In: BRANCO \& ROCHA (ed.). Poluição, Proteção e Usos Múltiplos de Represas.

MELLANBY, K. 1982. Biologia da poluição. São Paulo, EDUSP / EPU.

ODUM, E. 1988. Ecologia. Rio de Janeiro, Ed. Guanabara.

ROSA, R. 1990. Introdução ao sensoriamento remoto. Uberlândia, EDUFU.

SILVEIRA, S. S. B. \& SANT’ANNA, F. S. P. 1990. Poluição hídrica. In: MARGULIS, S. (ed.). Meio Ambiente: Aspectos Técnicos e Econômicos. Brasília, IPEA. 
